\title{
Children with seizures presenting to accident and emergency
}

\author{
R A Smith, T Martland, M F Lowry
}

\begin{abstract}
Objective-To analyse the diagnoses made in children presenting to an accident and emergency (A\&E) department with seizures.
\end{abstract}

Methods-All children who presented to a district general hospital A\&E department with seizures over a 1 year period were identified. A retrospective review of A\&E and hospital records was performed one year after they were first seen. The types of seizure, investigations performed, treatment given, and the range of associated diagnoses were ascertained.

Results-199 children (of 21795 attending A\&E in the year) had 254 visits with seizures, which represented $1 \cdot 2 \%$ of the child attendances at A\&E. Self referral occurred in $87 \%$, and 52 patients had established epilepsy. Febrile seizures were far the commonest type of first seizure $(n=75)$, but there were also 13 cases of symptomatic seizures resulting from various metabolic and neurological causes.

Conclusions-The children studied had a very different spectrum of problems from adults. A\&E staff should be aware of the range of problems in children who present with seizures. Experienced paediatric staff should be available to assist all A\&E departments where children are seen ( 7 Accid Emerg Med 1996;13:54-58)

Key terms: seizures; children; A\&E departments

The incidence of epilepsy is highest in early childhood. The cumulative incidence increases steadily with increasing age and the prevalence increases steadily until mid-childhood. ${ }^{1}$ An incidence of 4.3 per 1000 children under 10 years has recently been reported, ${ }^{2}$ which is similar to the incidence of $4 \cdot 1$ per 1000 children under 11 years in the National Child Development Study. ${ }^{3}$ Febrile convulsions, a specific seizure syndrome, are said to occur at least once in $2 \cdot 7 \%$ of children. ${ }^{4}$ Children experiencing a first seizure are likely to come to hospital as emergencies. Although there are studies of adults presenting to casualty with seizures $^{5}$ and similar studies from the United States that include children, ${ }^{6}$ there are no United Kingdom studies of children presenting to accident and emergency (A\&E) departments with seizures. Children presenting with के seizures have a potentially broad range of associated problems that require appropriate management. Such an analysis would be useful for planning district $\mathrm{A} \& \mathrm{E}$ and paediatric services.

\section{Methods}

We studied all children presenting as an ir emergency within one year to a district general hospital A\&E Department serving a population of 70000 children. Children presenting as an emergency, whether self referred or referred by their general practitioner (GP), are admitted through the children's A\&E department at Sunderland District General Hospital (SDGH). We obtained the names of all patients recorded as having a seizure, collapse, blackout, or "funny turn" from the A\&E register. One or more criteria were required: a description by an independent witness, an appropriate clinical history with postictal signs, a further seizure witnessed in the A\&E department, or loss of consciousness in a patient known to have epilepsy. The definition of a febrile seizure used in this study was an epileptic seizure occurring in a child aged 6 months to 5 years precipitated by a fever arising outside the nervous system. ${ }^{7}$ Clinical evidence of current infection was accepted in the absence of a clearly defined fever. The definitions of epilepsy and seizures were based on the proposals of the International League Against Epilepsy revised in 1981 and $1989 .^{8} 9$ All available case records were used in defining the seizure type in each individual. Children described as "known to have epilepsy" on A\&E records were confirmed as such by review of case records. The A\&E case record sheet and hospital records on all children were obtained and a standard form completed one year after initial presentation.

\section{Results}

Over one year, 21795 children attended the children's A\&E department. Of 314 cases initially ascertained, 40 were excluded on the above criteria, and 10 sets of notes $(3 \%)$ were unobtainable. In total, 199 patients (mean age $=4.48$ years, SD $4 \cdot 75$ ) had 254 visits with seizures $(1 \cdot 2 \%$ of all attendances). Most were under 3 years of age and the peak age of presentation was 2 years. There were 160 children who attended once and 39 who attended more than once. Self referral was the
General Hospital Child Health. Newcastle upon Tyne: Paediatrics R A Smith

M F Lowry Correspondence Consultant Paediatrician, York District Hospital, Wigginton Road, York YO3 7HE. 
Table 1 Emergency treatment of seizures. Episodes treated $=51(20 \%)$.

\begin{tabular}{lll}
\hline Treatment given & Episodes & Percent \\
\hline Diazepam PR & 38 & 74 \\
Diazepam IV & 14 & 27 \\
Paraldehyde PR & 4 & 8 \\
Paraldehyde IM & 8 & 15 \\
Phenytoin IV & 3 & 6 \\
Phenobarbitone IV & 1 & 2 \\
Mannitol & 9 & 18 \\
Oxygen & 18 & 35 \\
Glucose IV & 1 & 2 \\
Endotracheal intubation & 2 & 4 \\
\hline
\end{tabular}

$\mathrm{PR}=$ per rectum; $\mathrm{IV}=$ intravenous $; \mathrm{IM}=$ intramuscular.

commonest source of patients $(n=222 ; 87 \%)$. Twenty ( $8 \%$ ) were referred by their GP, and 12 $(5 \%)$ were sent from school. In 49 cases $(19 \%)$ the child was fitting on arrival to the department. Multiple seizures were experienced by 46 children (18\%). Anticonvulsant treatment was given in the $A \& E$ department in 51 instances $(20 \%)$. Details of treatment given are in table 1 .

\section{TYPE OF CASE}

The children can be divided into four broad groups: (1) those presenting with a first seizure; (2) those with established epilepsy; (3) those with febrile seizures; (4) those with status epilepticus.

\section{First seizure}

Details of follow up diagnoses of 118 children $(59 \%)$ presenting for the first time with a seizure are given in table 2 . Of these, 104 self referred $(88 \%), 12$ were referred by their GP $(10 \%)$, and two came directly from school. Most were admitted $(n=113 ; 96 \%)$. By far the largest group was 75 children $(63 \%)$ with febrile seizures. Many of these had underlying diagnoses which are presented in table 4 . In those who presented having had a first seizure there were 12 children $(10 \%)$ who were diagnosed as having epilepsy during the one year follow up period. Seven of these came initially with generalised tonic-clonic seizures, four had partial seizures (two with benign Rolandic epilepsy), and one had absence seizures. In 13 cases the seizure was symp-

Table 2 First seizure

\begin{tabular}{lr}
\hline Febrile seizures & 75 \\
Generalised seizures & \\
Idiopathic epilepsy & 8 \\
Isolated seizure & 8 \\
Myoclonic seizure & 1 \\
Symptomatic seizures & \\
Hypoglycaemia & 1 \\
Anoxic seizure & 1 \\
Self poisoning & 2 \\
Hypertension & 1 \\
Subarachnoid haemorrhage & 1 \\
Hydrocephalus & 1 \\
Encephalitis & 2 \\
Cerebral palsy and mental retardation & 3 \\
Head injury & 1 \\
Partial seizures & \\
Isolated seizure & 3 \\
Complex partial epilepsy & 2 \\
Rolandic epilepsy & 2 \\
Neonatal seizures & \\
Idiopathic & 2 \\
Fifth day fits & 1 \\
Myoclonic & 1 \\
Benign neonatal seizures & \\
Pyridoxine dependent epilepsy & 1 \\
Total & 118 \\
\hline
\end{tabular}

tomatic of some other significant pathology (table 2). In all 13 of these the seizure was a generalised tonic-clonic seizure. One of these children had a subarachnoid haemorrhage and died despite treatment with intravenous diazepam, phenytoin, and mannitol, intubation, and transfer to intensive care. Among the children presenting with their first seizure were six infants aged less than 3 months (neonatal group).

\section{Children with epilepsy}

Seventy eight $(31 \%)$ of all attendances were in 52 children who had epilepsy; 19 (26\%) attended more than once, and $49(63 \%)$ were admitted. In this group $64(82 \%)$ were self referrals, $10(13 \%)$ came from school, and only four $(5 \%)$ were referred by their GP. On 71 of these visits, children were already on anticonvulsant treatment, with 16 taking more than one drug. Further anticonvulsant treatment in the $\mathrm{A} \& \mathrm{E}$ department was given to only $15(19 \%)$ : 13 only received rectal diazepam, but two with status epilepticus required further treatment (see below). On only three occasions was rectal diazepam recorded as being given before admission to $\mathrm{A} \& \mathrm{E}$. On 16 occasions $(20 \%)$ the admission was the result of a febrile illness which may have precipitated the seizure. On two occasions children sustained minor head injuries following a seizure. The associated diagnoses in this group are given in table 3. Among those with mental retardation was a boy with Angelman's syndrome, a girl with severe unexplained intracerebral calcification, and a child with agenesis of the corpus callosum.

\section{Febrile seizures}

Febrile seizures led to 133 attendances (52\%) in 104 patients; $75(30 \%)$ had a first febrile seizure and 11 attended more than once with febrile seizures. Ward admission was needed on 115 occasions ( $86 \%)$. In 15 children the convulsion was atypical or complex in that there was either a focal element to the seizure, or multiple seizures occurred during one admission. Of the 15 of these children who required treatment in $\mathrm{A} \& \mathrm{E}, 13$ were given rectal diazepam and two with status epilepticus required further treatment (see below). None were given treatment before admission. Table 4 presents the underlying diagnoses in this group of children.

\section{Status epilepticus}

In 12 of the 254 attendances ( $5 \%$ ), the seizure either lasted longer than $30 \mathrm{~min}$ or there were

Table 3 Patients with established epilepsy

$\begin{array}{lr}\text { Epilepsy } & \\ \quad \text { Generalised tonic clonic } & 18 \\ \text { Partial } & 4 \\ \text { Epilepsy syndrome } & \\ \quad \text { Lennox Gastaut } & 1 \\ \text { Infantile spasms } & 1 \\ \quad \text { Juvenile myoclonic epilepsy (Janz) } & 1 \\ \text { Epilepsy and other diagnosis } & \\ \quad \text { Mental retardation/developmental delay } & 12 \\ \quad \text { Cerebral palsy } & 6 \\ \text { Cerebral palsy and mental retardation } & 9 \\ \text { Total } & 52\end{array}$


Table 4 Underlying diagnoses: febrile seizures

\begin{tabular}{lr}
\hline Viral & 38 \\
Otitis media & 33 \\
Tonsillitis & 12 \\
Gastroenteritis & 3 \\
Pneumonia & 1 \\
Herpes simplex stomatitis & 1 \\
Chickenpox & 2 \\
Urinary tract infection & 3 \\
No recorded diagnosis & 23 \\
\hline
\end{tabular}

multiple seizures with no period of waking between, that is, the patients had status epilepticus. In seven children this occurred with the first seizure. In 10 the seizures were generalised tonic-clonic and two were initially partial. One child had a subarachnoid haemorrhage, one had encephalitis, and two had febrile seizures. Four children had an established diagnosis of epilepsy, including three who also had cerebral palsy. Of this group, in addition to rectal and intravenous diazepam, all were given paraldehyde either rectally or intramuscularly, three were given phenytoin, and one phenobarbitone. Nine of this group were given mannitol. Two were intubated.

\section{INVESTIGATIONS}

The investigations performed are given in table 5. There was only one case of hypoglycaemia in a child with diabetes. The rest of the patients with abnormal results $(7 \%)$ had only mildly raised plasma glucose. All the full blood counts performed were in febrile children. The commonest abnormality was a raised white cell count. In $31 \%$ of cases urea and electrolytes estimations were performed and there was a high incidence of abnormality $(54 \%)$. One child with hypertensive encephalopathy had a raised creatinine and all the others had only mildly depressed plasma sodium concentrations (mean $=131 \mathrm{mmol} /$ litre). On 27 occasions, anticonvulsant concentrations were measured: all these patients had epilepsy and on 10 occasions (37\%) the level was below the therapeutic range. Twenty two cases had lumbar punctures when intracranial infection was suspected on clinical history or examination; of these only three were abnormal, one with a subarachnoid haemorrhage and two with presumed viral encephalitis. These three cases also had urgent CAT scans. The case with a subarachnoid haemorrhage was the only one with abnormal CAT (computerised axial tomography) scan findings. Three cases with partial seizures had follow up scans which were normal.

Table 5 Investigation (all fits)

\begin{tabular}{llc}
\hline Investigation & Number (\%) & Abnormal (\%) \\
\hline Bm-Test & $86(34)$ & 7 \\
Blood sugar & $66(26)$ & 6 \\
Full blood count & $95(37)$ & 43 \\
Urea and electrolytes & $80(31)$ & 54 \\
Calcium & $32(12)$ & 6 \\
Blood culture & $56(22)$ & 0 \\
Skull $x$ ray & $19(7)$ & 0 \\
Chest $x$ ray & $55(22)$ & 7 \\
Lumbar puncture & $22(11)$ & 14 \\
Anticonvulsant levels & $27(11)$ & 37 \\
Urgent CAT scan & $3(1)$ & 33 \\
\hline
\end{tabular}

$\mathrm{CAT}=$ computerised axial tomography.

\section{Discussion}

The $1.2 \%$ incidence of seizures in a population of children's A\&E attenders is the same as that $c$ reported by McKee et $a l^{5}$ for adults attending casualty, but more than the $0.7 \%$ reported by Krumholz et al. ${ }^{6}$ In our children's A\&E department, $60 \%$ of attendances are for trauma. Seizures therefore represent $2.9 \%$ of medical cases seen. Over the whole spectrum of children presenting with seizures we found a range of diagnoses and associated problems very different from those reported in adults. Krumholz noted that alcohol abuse was a significant complicating factor in $41 \%$ of adult patients. McKee found a strong association with alcohol dependence $(60 \%)$ and head $\stackrel{\mathscr{Q}}{\Omega}$ injury $(15 \%)$. In our study only one child क presented with a seizure following a head $\vec{\circ}$ injury. The hospital admission rate of $80 \%$ in our series is partly a reflection of the higher $\vec{\omega}$ incidence of first seizures and partly of the considerable anxieties generated by any seizure in a child. The admission rate was only $31.5 \%$ in the series of Krumholz et al but was similar for first seizures $(82 \%)$ in the series from $\overrightarrow{i r}$ $\mathrm{McKee}$ and his colleagues. Verity et al reported that $74 \%$ of 83 children with a first seizure were admitted to hospital, although the route of $\vec{c}$ referral is not commented on. ${ }^{2}$ The follow up rate for our series was significantly higher than that of McKee et al (89\% compared to $64 \%$ ). Those children (19\%) not given follow up $\overrightarrow{0}$ appointments after admission were pre- \% dominantly those with simple febrile seizures. The high self referral rate in our study reflects the local availability of services. The very existence of a children's A\&E department appears to attract patients. It also reflects that for, most parents, seeing their child having a seizure is a frightening experience leading to an understandable wish to seek urgent medical advice.

The incidence of first seizures in Sunderland $(59 \%)$ was higher than figures given by both McKee et $a l^{5}$ (44\%) and Krumholz et $a l^{6}$ (34\%). This reflects the higher incidence of epilepsy and febrile seizures in childhood and is to be expected. The largest group presenting were those with febrile seizures $(52 \%)$. The 을 study by Krumholz reported an incidence of $D$ $48 \%$ for febrile seizures. One surprising finding 을 in our study is the lower than expected $N$ numbers of complex febrile seizures (15 of 33 attendances). Some of the children with 0 established epilepsy also presented during $\omega$ febrile illness with deteriorating seizure control. In these children not only does one need to consider the management of the seizure but also the source of the fever. Three of the children with first febrile seizures had urinary tract infections leading to a need for further assessment of their renal tract. The range of causes of fever were very similar to $\triangle$ those previously reported. ${ }^{10}$ The distribution of $\bar{P}$ seizure types in the groups with a first seizure 8 is similar to that reported by Verity ${ }^{2}$ but as this is not a population based study, no firm 흠 comparisons can be made. Generalised tonicclonic seizures occurred in $61 \%$ and other seizure types in $8 \%$ in one study ${ }^{6}$ and 
generalised tonic-clonic seizures $(83.5 \%)$ and complex partial seizures $(11 \%)$ were recorded in another ${ }^{5}$. It is important to note, however, that children with complex partial seizures and even simple absence seizures self refer as an emergency. This is presumably due to the concern created by the episode.

In the series reported by Verity et $a l,{ }^{2} 28 \%$ of 84 patients had symptomatic seizures. In our study (excluding febrile seizures and neonatal seizures), of 37 first seizures, 13 (35\%) were symptomatic. This group of patients are particularly important and generally have a poor prognosis. ${ }^{2}$ Many of the children with epilepsy had associated neurological problems and mental retardation, making clinical assessment in the postictal state difficult for medical staff inexperienced in dealing with such cases. The incidence of status epilepticus in our study was $5 \%$. McKee et al reported an incidence of $2 \%$ and Krumholz et al 7\%.5 6

The investigation of patients presenting as an emergency has been reported in several studies $^{11-14}$ as have the investigation of children with febrile seizures. ${ }^{101516}$ These show that seizures are rarely due to derangements in serum biochemistry and that when they are the abnormality can usually be predicted from the clinical history. Our study supports these findings. The commonest abnormalities, a mildly depressed plasma sodium and mildly raised plasma glucose, are probably a result of the fever or seizure rather than the cause. ${ }^{11} 17$ Unless the seizure is prolonged or their is a factor in the history suggesting an abnormality we would not recommend routine electrolyte measurement. We would recommend that all children have measurement of blood glucose during a seizure and blood pressure at some stage during initial $\mathrm{A} \& \mathrm{E}$ assessment. Skull $x$ rays are rarely of any use in the investigation of children with seizures. ${ }^{18}$ Investigation of an infant with a non-febrile seizure is indicated as there is an extensive differential diagnosis. The investigations would be based on the history and examination.

Patients with epilepsy often had subtherapeutic anticonvulsant levels. This has been noted in other studies. ${ }^{6} 131920$ We would recommend checking anticonvulsant levels in children with known epilepsy mainly as a guide to compliance with treatment.

Drug treatment was given on 51 occasions in the A\&E department. A standard protocol was followed in most cases, with rectal diazepam being used initially, then either intravenous diazepam or rectal paraldehyde, and if the child continued to convulse, intravenous phenytoin. Twenty six of the 38 children who received rectal diazepam required no further treatment. All of the children requiring more than intravenous diazepam had status epilepticus $(n=12)$. Mannitol was given only to patients in status epilepticus where raised intracranial pressure as a result of the prolonged seizure was suspected, that is, in children who had stopped convulsing but who were still unconscious. Diazepam has been the standard initial treatment for prolonged seizures and is effective in $85 \%$ of cases. Lorazepam may be preferable as it has a longer half life and no slowly degraded metabolites. Its action, however, is slower in onset. It may also cause less respiratory depression than diazepam, especially in patients who have previously received phenobarbitone. ${ }^{21}$

Only three children were given diazepam rectally before admission. This is a lower figure than one would expect considering the high percentage of cases of children with known epilepsy. It may, however, reflect the fact that the patient group that attends casualty with seizures (in this study on a frequent and recurrent basis) is a group that may not use self administered treatment. This is one area for further study and could be a target for health education as there is considerable potential within this group to reduce attendance at $A \& E$. This finding may also reflect the relative lack of specific outpatient services for children with epilepsy. None of the patients in this study suffered respiratory depression from the drugs given. It is interesting to note that only two were intubated, both of whom were transferred to intensive care.

We recommend that units develop local guidelines for the management of status epilepticus in children which may vary depending on the local availability of services. A full discussion is beyond the scope of this paper and has recently been extensively reviewed. ${ }^{22} 23$

\section{CONCLUSION}

Children presenting as an emergency with a seizure represent a heterogeneous group and often have complex problems. Many have significant accessory diagnoses and in some children the seizure can be the presenting symptom of serious underlying pathology. $A \& E$ staff should be aware of the different range of problems in children who present with seizures. Experienced paediatric staff should be available to assist all $\mathrm{A} \& \mathrm{E}$ departments where children are seen.

1 Shorvon SD. Epidemiology, classification, natural history, and genetics of epilepsy. Lancet 1990;336:93-6.

2 Verity CM, Ross EM, Golding J. Epilepsy in the first 10 years of life: findings of the child health and education study. BMF 1992;305:857-61.

3 Ross EM, Peckham CS, West PB, Butler NR. Epilepsy in childhood: findings from the National Child in childhood: findings from the Natior

4 Robinson RI. Febrile convulsions. BMF 1991;303:1345-6.

5 McKeen PJW, Wilson EA, Dawson JA, Larkin JG, Brodie MJ. Managing seizures in the casualty department. BMF 1990;303:978-9.

6 Krumholz A, Grufferman S, Orr ST, Stern B. Seizures and seizure care in an emergency department. Epilepsia 1989;30:175-81.

7 Neville B. What do we mean by febrile convolusion? Paper prepared for workshop of the Research Unit of Royal College of Physicians and British Paediatric Association, 1991.

8 The Commission on Classification and Terminology of the International League Against Epilepsy. Proposal for revised clinical and electroencephalographic classification of epileptic seizures. Epilepsia 1981;22:489-501.

9 The Commission on Classification and Terminology of The International League Against Epilepsy. Proposal for revised classification of epilepsies and epileptic syndromes. Epilepsia 1989;30:389-99.

10 Rutter N, Smales ORC. The role of routine investigation in children presenting with their first febrile convlsion. Arch Dis Child 1977;52:188-91.

11 Powers RD. Serum chemistry abnormalities in adult patients with seizures. Ann Emerg Med 1985;14:416-20.

12 Eisner RF, Turnbull TL, Howes DS, Gold IW. Efficacy of a "standard" seizure work up in the emergency department. Ann Emerg Med 1986;15:69-75. 
13 Turnbull TL, Vanden Hoek TL, Howes DS. Utility of laboratory studies in the emergency department in patients with a new onset seizure. Ann Emerg Med 1990;00:373-7.

14 Baraf LJ, Schriger DL, Stakman S. Compliance with a standard for the emergency department management of epileptics who present after an uncomplicated convulsion. Ann Emerg Med 1990;19:367-71.

15 Rutter N, Smales ORC. Calcium, magnesium and glucose levels in blood and CSF of children with febrile covels in blood and CSF of children

16 Rutter N, O'Callaghan MJ. Hyponatraemia in children with febrile convulsions. Arch Dis Child 1978;53:85-8.

17 Sharples PM, Seckl JR, Human D, Lightman SL, Dunger in patients with and without fever. Arch Dis Child 1992;67:998-1002.
18 Committee on Radiology. Skull roentgenography of infants. Children with convulsive disorders. Pediatrics $1978 ; 62$ : 835-7.

19 McGlove R, Pritty P. Measuring anticonvulsant levels in the accident and emergency department. Arch Emerg Med 1986;3:141-3.

20 Peterson GM, McClean S, Millingham KJ. Determination of patient compliance with anticonvulsant therapy. Epilepsia 1982;23:607-13.

21 Lacey DJ, Singer WD, Horwitz SJ, Gilmore H. Lorazepam therapy of status epilepticus in children and adolescents. therapy of status epilepticus in children and adolescents. f Pediatr 1986;108:771-4.

, Hussain IHMI. Status epilepticus. I. Pathogenesis. Dev Med Child Neurol 1991;33:3-17.

23 Brown JK, Hussain IHMI. Status epilepticus. II. Treatment. Dev Med Child Neurol 1991;33:97-109. 